Contents lists available at Journal Redwhitepress
Journal of Educational and Learning Studies
ISSN: 2655-2760 (Print) ISSN: 2655-2779 (Electronic)
Journal homepage: http://journal.redwhitepress.com/index.php/iles

\title{
Application of Rasch Rating Scale Model to Analyze the Fear of Missing Out a Smartphone
}

\author{
Alizamar Alizamar \\ ${ }^{1}$ Guidance and Counseling Department, Universitas Negeri Padang, Indonesia
}

\begin{tabular}{l}
\hline Article Info \\
Article history: \\
Received Feb $12^{\text {th }}, 2019$ \\
Revised Apr $20^{\text {th }}, 2019$ \\
Accepted Jul 6 ${ }^{\text {th }}, 2019$ \\
\hline
\end{tabular}

\section{Keyword:}

Fear of Missing Out (FoMO)

Rating Scale

Threshold

Smartphone

\begin{abstract}
The presence of smartphones is one of the technological advancements that have contributed greatly to changes in social behavior. This led to the inception of the Fear of Missing Out (FoMO) smartphone device. The purpose of this study therefore was to determine the right instrument to measure the FoMO smartphone by analyzing response points obtained from respondents. The study sample consisted of three groups of test subjects, from large city, small town and villages with $\mathrm{n}$ values of 226,248 , and 55 respectively. The data in this study were obtained using the 5-point Likert scale politomy data from a Fear of Missing out scale instrument, distributed online. The research data were analyzed using the Rasch model by testing rating scale analysis through Threshold. The results showed that the rating scale answered choices turned into a 3-point Likert scale with those not right, less right, and very right.
\end{abstract}

(C) 2019 The Authors. Published by Redwhitepress.

This is an open access article under the CC BY-NC-SA license (https://creativecommons.org/licenses/by-nc-sa/4.0/

\section{Corresponding Author:}

Alizamar Alizamar,

Universitas Negeri Padang

Email: alizamar@konselor.org

\section{Introduction}

The rapid development of technology, information and communication is tremendously increasing in this millennial era. Individuals cannot be far from technology, owing to the need for faster access to various types of information, interactions, and faster communication (Au-Yong-Oliveiraa, Gonçalvesb, Martinsb, \& Branco, 2018). However, there are consequences associated with this rapid development in technology, such as excessive usage (Davis, 2001; Sigerson, Angel, Cheung, \& Cheng, 2017), high levels of involvement (Charlton \& Danforth, 2007), and addiction (Turel, Serenko, \& Giles, 2011). The technology in the field of communication led to the development of a smartphone (David, 2019).

According to Bauman 2016, the technological advancement of smartphones has caused numerous change in the lives of people, especially teenagers. This change in addition to having a positive impact on adolescence also has a negative impact that threatens their development. Due to the numerous kinds of facilities used to access information through smartphones, teenagers are becoming addicted to its usage. Smartphones have become an inseparable part of everyday life and most people carry it all the time (Choi \& Lim, 2016; Smura, Kivi, \& Töyli, 2009).

Based on the latest estimates (Statista, 2015), the number of smartphone users worldwide was estimated at 2.16 and 2.56 billion people in 2016 and 2018, respectively with a high demand for its usage in telecommunications sector in Turkey. This is seen from the telecommunications sector which suggests an increase in smartphone purchases with supporting $4 \mathrm{G}$ networks up to 50\% (Çelik, Eygü, \& Oktay, 2015; GfK, 
2015). Young (2011) revealed that $98 \%$ of internet users between the ages of $16-20$ years have at least one smartphone and spend four hours online daily.

Aykanat, Y1ldiz, \& Çelik (2016) found students at the University of Turkey that spend less than 1 hour are $23.4 \%, 1$ to 2 hours (27\%), 2 to 3 hours (13.1\%), 3 up to 4 hours (5.1\%), 4 to 5 hours (4.9\%) and more than 5 hours (14.4). Karthik Venkatakrishnan, the Regional Director, of Digital GFK Asia, conducted a leading research in Germany stating that the average Indonesian spent 5.5 hours per day using a smartphone, with $96 \%$ internet users. Chang et al., 2019, stated that children in Taiwan spend 11 hours per week using either a smartphone or tablet (Chang et al., 2019). The prevalence of smartphone addiction among fifth graders is $15.2 \%$ with Fear of Missing Out (FoMO) which creates feelings of discomfort, anxiety when information is not met through internet access (Young, 2010).

Furthermore, excessive usage, leads to depression, anxiety, and quality of sleep (Demirci, Akgönül, \& Akpinar, 2015). Durak (2018) found a connection between smartphone addiction and depression, anxiety, and FoMO. In addition, its excessive usage, is a sign of addiction (Kibona \& Mgaya, 2015) and leads to pubbing behavior (Afdal et al., 2019). Also, smartphone addiction is an attachment that might trigger social problems such as withdrawal, difficulty in carrying out daily activities, and disruption in impulse control (Kwon, Lee, Won, Park, Min, Hahn, \& Kim, 2013). Individuals suffering from its addiction, show a new behavior, which is far more sensitive compared to the surrounding environment, thereby making it a problem (Salehan \& Neghaban, 2013).

This condition draws the attention of researchers in developing a gauge for addicts (Csibi, Demetrovics, \& Szabo, 2016; Csibi, Griffiths, Cook, Demetrovics, \& Szabo, 2018) using the Smartphone Application-Based Addiction Scale (SABAS) developed by (Csibi et al., 2018) which consists of six items. This reduces addiction using a six-point Likert point scale that ranges from 1 (strongly disagree) and 6 (strongly agree), the response points with higher scores in SABAS indicate a greater likelihood of risking addiction to the use of smartphones (Leung et al., 2019). In addition, the Internet Gaming Disorder Scale-Short Form (IGDS-SF9) developed by Griffiths \& Pontes (2014) and consisting of nine ED criteria, with five Likert scale scales ranging from 1 (never) to 5 (very often) was also utilized. However, the two instruments failed to display a rating scale validation, such as how the respondent determines the response point or whether they are not confused.

Based on the explanation above, in a valid and reliable measuring instrument must have a good rating scale in determining the response point. This acts as part of the evaluative criteria and assessment categories that indicate the extent to which certain behaviors, skills or strategies are displayed by an individual (Vagle, 2014). The contents of the rating scale represent the choices made during the design of what was assessed (Stiggins, Arter, Chappuis, \& Chappuis, 2006). Assuming the it makes no sense (the assessment is too much, little or irrelevant), then the interpretation and use of scores derived from the instrument will be erroneous in making conclusions (Tierney \& Simon, 2004). The purpose of this study is to determine the right instrument to measure the fear of missing out (FoMO) smartphone by paying attention to the response points given by the respondents.

\section{Method}

The study sample consisted of 519 students in three test subject groups, with the sampling technique conducted using purposive random sampling technique. The entire study sample consisted of three groups of tests subjects' from the big city, small town and village with $\mathrm{n}$ values of 226, 248, and 55 respectively. Data for each group of test subjects was collected through the Fear of Missing out scale developed by (Przybylski, Murayama, Dehaan, \& Gladwell, 2013), which was distributed online. The questionnaire uses a 5-point Likert scale with the number of items 19 . The research data were analyzed using the Rasch model by testing rating scale analysis through Threshold (Alagumalai, Curtis, \& Hungi, 2005; Bond \& Fox, 2015; Sumintono \& Widhiarso, 2015).

\section{Results and Discussions}

To achieve the objectives of this study two stages of assessment are carried out to assess: (1) the quality of the FoMO instrument, (2) the validity of the rating scale given the FoMO test, which is explained as follows:

\section{Quality of FoMO Instruments}

The instrument is said to be good when measuring correctly. In Table 1 the quality of the FoMO instrument is conveyed. 
Table 1. Quality of FoMO Instruments

\begin{tabular}{lccc}
\hline \multicolumn{1}{c}{ Measure } & \multicolumn{3}{c}{ Implementation } \\
\cline { 2 - 4 } Mean Person & $\begin{array}{c}\text { The Subject } \\
\text { Group Test 1 }\end{array}$ & $\begin{array}{c}\text { The Subject } \\
\text { Group Test 2 }\end{array}$ & $\begin{array}{c}\text { The Subject } \\
\text { Group Test 3 }\end{array}$ \\
\cline { 2 - 4 } Infit MNSQ Item & -1.09 & -1.05 & -1.06 \\
Outfit MNSQ Item & 1.00 & 1.00 & 1.01 \\
Separation Item & 1.02 & 1.03 & 1.01 \\
Separation Person & 9.23 & 9.69 & 4.24 \\
Raw variance explained by measures & 3.19 & 2.53 & 2.40 \\
Reliability Person & $54.5 \%$ & $50.1 \%$ & $47.6 \%$ \\
Reliability Item & .91 & .87 & .85 \\
Cronbach Alpha (Kr-20) & .99 & .99 & .95 \\
\hline
\end{tabular}

Based on Table 1 above, the mean values of the 1, 2, and 3 -person test are-1.09, -1.05 , and -1.06 respectively. This means that the mean person value of all tests tends is below the item. Furthermore, the score of each reliability person-test are $0.91,0.87$, and 0.85 respectively. While the reliability scores are $0.99,0.99$, and 0.95 . This shows that the quality of the answers given by each person to the test is excellent, and the quality of the items used in the measurement is special. While the value of each test on Cronbach's alpha (KR20 ) is $0.93,0.90$, and. 88 , which indicate excellent interaction between people.

Besides that, the item sensitivity value for each test tends to approach +1.00 logit for INFIT MNSQ, and MNSQ OUTFIT. This shows that suitability is infit and outfit from a mean square value of 1.0 (Alagumalai et al., 2005; Bond \& Fox, 2015; Sumintono \& Widhiarso, 2015). Furthermore, the value of raw variance explained by measures in each test is above $40 \%$, this indicates that the minimum one-dimensional requirement of $40 \%$ has been fulfilled (Linacre, 2011). Therefore, this condition is fulfilled using 19 items in the FoMO instrument for measuring conditions in cities, towns, and villages. In line with the research carried out by Lebanon Nahas, Hlais, Saberian, \& Antoun (2018) the scale used to measure valid and reliable smartphone is The Mobile Phone Problematic Use Scale (MPPUS-10) with 24 number of items, estimated smartphone usage of $15 \%$, margin of error $5 \%$, and reliability of 0.95 .

\section{The rating scale given by FoMO can be understood by the respondents}

A good instrument does not confuse the respondent in choosing answers and its rating scale must be properly understood by the respondent. The threshold parameter between ratings used to indicate the standard is 1.4 - 5.0 logit with a 5-point Likert scale (Sumintono \& Widhiarso, 2015). The Threshold analysis between ratings is presented in Table 2 below.

Table 2: Rating scale uses Andrich Threshold

\begin{tabular}{clccc}
\hline Category & Label & $\begin{array}{c}\text { The Subject } \\
\text { Group Test 1 }\end{array}$ & $\begin{array}{c}\text { The Subject } \\
\text { Group Test 2 }\end{array}$ & $\begin{array}{c}\text { The Subject } \\
\text { Group Test 3 }\end{array}$ \\
\hline $\mathbf{1}$ & Not right & None & None & None \\
$\mathbf{2}$ & less right & -1.64 & -1.55 & -1.55 \\
$\mathbf{3}$ & Quite right & -.83 & -.68 & -.54 \\
$\mathbf{4}$ & Right & .17 & .04 & .07 \\
$\mathbf{5}$ & Very right & 2.30 & 2.19 & 2.03 \\
\hline
\end{tabular}

Based on Table 2 above, respondents tend to choose from the answers given to the FoMO instruments in each test. The results indicates the choices made by respondents, which is stated from the threshold value of 1 to 5 which is different in each group of test subjects 1,2 , and 3 . Therefore, the subject group tests indicated the answer was incorrect and correct for the respondent. However, the choice of answers ranges from "not right," "quite right," and "right" in the FoMO instrument. This is because the respondents have difficulty in giving the answer choices of "less right," "quite right," and "right," with the threshold value less than 1.4 in the answer choices.

Lin et al. (2014) show that smartphone addiction involves compulsive behavior, tolerance, withdrawal, and functional disorders. Kwon et al. (2013) argue that its usage involve disruption of everyday life, positive anticipation, withdrawal, cyberspace-oriented relationships, excessive use, and tolerance. In 2014, Kwon et al. developed a ten-point Likert scale inventory involving the six symptoms mentioned above and adopted 31 and 
33 as their respective cutoff points for diagnosing male and female smartphone addiction by analyzing the Receiver Operating Characteristics (ROC).

Korean researchers developed a self-diagnostic scale, namely: Smartphone Addiction Scale (SAS) and internet addiction (Kwon, Lee, Won, Park, Min, Hahn, Gu, et al., 2013). The scale used for internet addiction is the $\mathrm{K}$ scale and the Y scale modified by Kimberly Young. The $\mathrm{K}$ scale with Smartphone Addiction Scale (SAS) uses a 4-point response (Kim, Chung, Lee, Kim, \& Cho, 2008) and Y Scale with Smartphone Addiction Scale (SAS) using a 5-point response, while both $\mathrm{K}$ scale and $\mathrm{Y}$ has an internal consistency of 0.95 . Based on the results of the explanation above, the researcher clarified the respondent's response to the choice of answers using the FoMO instrument presented in Figures 1, 2, and 3.

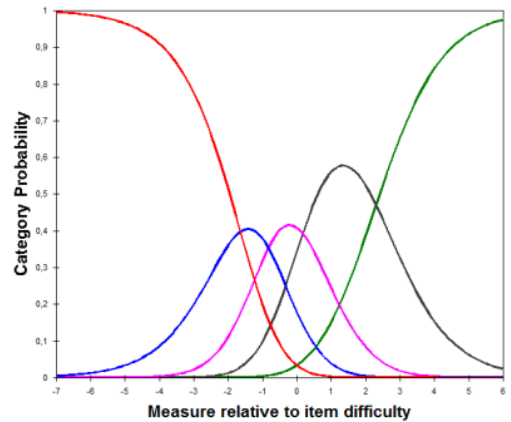

1.p1

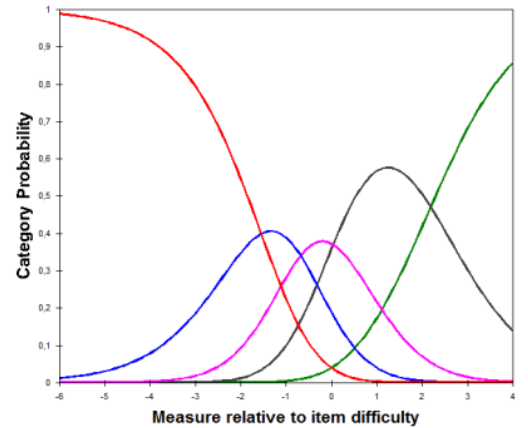

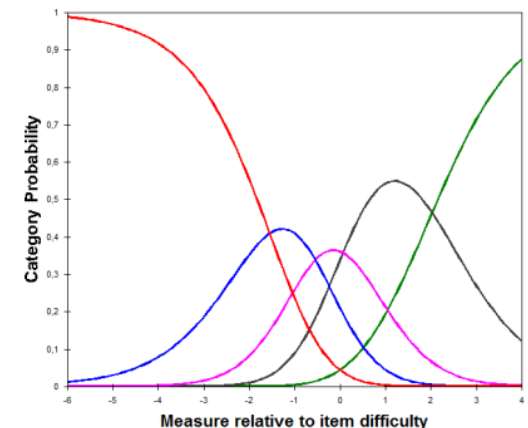

Figure 1: The Subject Group Test 1 Figure 2. The Subject Group Test 2 Figure 3. The Subject Group Test 3

In figure 1 above, stated that respondents from big cities tend to choose answer 1(not right), and 5 (very right), with difficulty in picking 2 (less right), 3 (quite right), and 4 (right). While Figure 2 shows that the test in small cities is similar to those in big cities with regards to answers on FoMO instruments. Furthermore, in figure 3 the village test still tends to be the same in responding to the answers on the FoMO instrument. This means that the choice of answers given by it needs to be considered because the findings of the experimental group test 1,2, and 3 are different with same response choices. Respondents in the three tests were still confused in choosing the answers given by the FoMO instrument as they were still considered difficult in accordance to big cities, towns, and villages. Assuming the line which indicates the response point on the inventory is not removed or combined, it tends to have an impact in providing the response point. The social bias in question is the desire to make the feelings of the interviewer happy as they tend to answer by choosing neutrally (middle point) (Garland, 1991). From the findings of this study, it is analyzed that people living in big cities, small towns and villages have difficulties with rating scales or with numerous response points.

Based on the Threshold analysis there is adequate need to merge the choice of answers such as "not right," "quite right," and "right." Therefore, the Threshold value is 1.4 because the parameter between the ratings used to show the standard is 1.4 - 5.0 logit (Sumintono \& Widhiarso, 2015). Based on these results it is stated that the answer choice after the combined Threshold value becomes a 3-point Likert scale.

\section{Conclusions}

The findings of the 19 items used in the FoMO instrument are valid and reliable (.99). Furthermore, for the rating scale on Threshold analysis, the answer option turns into a 3-point Likert scale with choices consisting of "not right," "less right," and "very right." This is due to the combination of the choice of answers which is "less right," "quite right," and "right." Therefore, the Threshold value is 1.4 because its parameter is 1.4 - 5.0 logit (Sumintono \& Widhiarso, 2015). It is stated that the FoMO instrument is used in cities, towns, and villages without any confusion in responding to the choice of answers.

\section{References}

Afdal, A., Alizamar, A., Ifdil, I., Ardi, Z., Sukmawati, I., Zikra, Z., ..., \& Hariyani, H. (2019). An Analysis of Phubbing Behaviour: Preliminary research from counseling perspective. Advances in Social Science, Education and Humanities Research, 295(ICETeP 2018), 270-273.

Alagumalai, S., Curtis, D. D., \& Hungi, N. (2005). a Pplied Rasch Measurement : a Book of Exemplars Education in the Asia-Pacific Region: Issues, Concerns and Prospects. Netherlands: Springer.

Au-Yong-Oliveiraa, M., Gonçalvesb, R., Martinsb, J., \& Branco, F. (2018). The social impact of technology on millennials and consequences for higher education and leadership. Telematics and Informatics, 35(4), 
954-963.

Aykanat, Z., Yıldız, T., \& Çelik, A. K. (2016). A Structural Equation Modeling of University Students' Smartphone Dependence in An Emerging Country. Peer-Reviewed Academic Journal Innovative Issues and Approaches in Social Sciences, 9(3), 108-121.

Bauman, A. (2016). Students' perceptions of the use of technology in cross-cultural communication. Higher Education, Skills and Work-Based Learning, 6(2), 193-207.

Bond, T. G., \& Fox, C. M. (2015). Applying the Rasch Model, Fundamentals Measurement in the Human Science (3rd edition). New York: Routledge.

Çelik, A. K., Eygü, H., \& Oktay, E. (2015). A study on factors influencing young consumers' smartphone brand preference in Erzurum, Turkey. European Journal of Business and Economics. Journal of Business and Economics, 10(2), 24-31.

Chang, F. C., Chiu, C. H., Chen, P. H., Chiang, J. T., Miao, N. F., Chuang, H. Y., \& Liu, S. (2019). Children's use of mobile devices, smartphone addiction and parental mediation in Taiwan. Computers in Human Behavior, 93, 25-32.

Charlton, J. P., \& Danforth, I. D. (2007). Distinguishing addiction and high engagement in the context of online game playing. Computers in Human Behavior, 23(3), 1531-1548.

Choi, S. B., \& Lim, M. S. (2016). Effects of social and technology overload on psychological well-being in young South Korean adults: The mediatory role of social network service addiction. Computers in Human Behavior, 61, 245-254.

Csibi, S., Demetrovics, Z., \& Szabo, A. (2016). Hungarian adaptation and psychometric characteristics of Brief Addiction to Smartphone Scale (BASS). Psychiatria Hungarica, 3(1), 71-77.

Csibi, S., Griffiths, M. D., Cook, B., Demetrovics, Z., \& Szabo, A. (2018). The psychometric properties of the Smartphone Application-Based Addiction Scale (SABAS). International Journal of Mental Health and Addiction, 16(2), 393-403.

David, A. E. (2019). Are smartphones really that bad? Improving the psychological measurement of technology-related behaviors. Computers in Human Behavior, 97, 60-66.

Davis, R. A. (2001). A cognitive-behavioral model of pathological internet use. Computers in Human Behavior, $17(2), 187-195$.

Demirci, K., Akgönül, M., \& Akpinar, A. (2015). Relationship of smartphone use severity with sleep quality, depression, and anxiety in university students. Journal of Behavioral Addictions, 4(2), 85-92.

Durak, H. Y. (2018). Investigation of nomophobia and smartphone addiction predictors among adolescents in Turkey: Demographic variables and academic performance. The Social Science Journal, In Press, Corrected Proof.

Garland, R. (1991). The Mid-Point on a Rating Scale: Is it Desirable? Marketing Bulletin, 2(1), 66-70.

GfK. (2015). GfK TEMAX ${ }^{\circledR}$ Türkiye 2015 İkinci Çeyrek Sonuçları (in Turkish). Available at: http://www.gfk.com/tr/icgoerueler/pressrelease/tueketici-teknolojisi-ueruenleri-pazari-2-ceyrekte-168bueyuedue.

Griffiths, M. D., \& Pontes, H. M. (2014). Internet addiction disorder and internet gaming disorder are not the same. Journal of Addiction Research and Therapy, 5(4), e124.

Kibona, L., \& Mgaya, G. (2015). Smartphones' effects on academic performance of higher learning students. Journal of Multidisciplinary Engineering Science and Technology (JMEST, 2(2), 777-784.

Kim, D., Chung, Y., Lee, E., Kim, D., \& Cho, Y. (2008). Development of internet addiction proneness scaleshort form (KS scale). The Korea Journal of Counseling, 9(4), 1703-1722.

Kwon, M., Lee, J. Y., Won, W. Y., Park, J. W., Min, J. A., Hahn, C., ... Kim, D.-J. (2013). Development and validation of a smartphone addiction scale (SAS). PloS One, 8(2), e56936.

Kwon, M., Lee, J. Y., Won, W. Y., Park, J. W., Min, J. A., Hahn, C., \& Kim, D. J. (2013). The smartphone addiction scale: Development and validation of a short version for adolescents. PloS One, 9(5), 1-8.

Leung, H., Pakpour, A. H., Strong, C., Lin, Y. C., Tsai, M. C., Griffiths, M. D., ..., \& Chen, I. H. (2019). Measurement invariance across young adults from Hong Kong and Taiwan among three internet-related addiction scales: Bergen Social Media Addiction Scale (BSMAS), Smartphone Application-Based Addiction Scale (SABAS), and Internet Gaming Disorder Scale-Short. Addictive Behaviors.

Lin, Y. H., Chang, L. R., Lee, Y. H., Tseng, H. W., Kuo, T. B., \& Chen, S. H. (2014). Development and validation of the Smartphone Addiction Inventory (SPAI). PloS One, 9(6), 1-5.

Linacre, J. M. (2011). A User's Guide to WINSTEPS Ministeps Rasch-Model Computer Programs. https://doi.org/ISBN 0-941938-03-4

Nahas, M., Hlais, S., Saberian, C., \& Antoun, J. (2018). Problematic smartphone use among Lebanese adults aged 18-65 years using MPPUS-10. Computers in Human Behavior, 87, 348-353.

Przybylski, A. K., Murayama, K., Dehaan, C. R., \& Gladwell, V. (2013). Motivational, emotional, and behavioral correlates of fear of missing out. Computers in Human Behavior, 29(4), 1841-1848. 
https://doi.org/10.1016/j.chb.2013.02.014

Salehan, M., \& Neghaban, A. (2013). Social networking on Smartphone: When mobile phone become addictive. Computers in Human Behavior, 34(1), 2632-2639.

Sigerson, L., Angel, Y.-L. L., Cheung, M. W.-L., \& Cheng, C. (2017). Examining common information technology addictions and their relationships with non-technology-related addictions. Computers in Human Behavior, 75, 520-526.

Smura, T., Kivi, A., \& Töyli, J. (2009). Smura, T., Kivi, A., \& Töyli, J. (2009). A framework for analysing the usage of mobile services. Info, 11(4), 53-67.

Statista. (2015). Number of smartphone users worldwide from 2012 to 2018 (in billions). Available at: http://www.statista.com/statistics/330695/number-of-smartphoneusers-worldwide/.

Stiggins, R., Arter, J., Chappuis, J., \& Chappuis, S. (2006). Classroom assessment for student learning -Doing it right, using it well. Portland. OR: Educational Testing Service.

Sumintono, B., \& Widhiarso, W. (2015). Aplikasi Pemodelan Rasch pada Assessment Pendidikan. Bandung: Trim Komunikata.

Tierney, R., \& Simon, M. (2004). What's still wrong with rubrics: focusing on the consistency of performance criteria across scale levels. Practical Assessment, Research \& Evaluation, 9(2), 1-10.

Turel, O., Serenko, A., \& Giles, P. (2011). Integrating technology addiction and use: An empirical investigation of online auction users. MIS Quarterly, 35(4), 1043-1062.

Vagle, N. . (2014). Design in Five: Essential Phases to Create Engaging Assessment Practice. Citizen: Solution Tree Press.

Young, K. S. (2010). Internet addivtion: a handbook and guide to evaluation and treatment. Canada: John Wiley \& Sons, Inc.

Young, K. S. (2011). Prevalence Estimate and Etiologic Models of Internet Addiction. In K. S. Young, \& C. N. Abreu, Internet Addiction: A Handbook and Guide to Evaluation and Treatment. New Jersey: John Wiley \& Son, Inc. 